Images du travail, travail des images

6-7| 2019

Femmes au travail\&nbsp: quelles archives visuelles ?

\title{
Religieuses et infirmières : des femmes dans un monde d'hommes
}

Geneviève Piché

\section{(2) OpenEdition \\ Journals}

Édition électronique

URL : http://journals.openedition.org/itti/775

DOI : $10.4000 /$ itti. 775

Éditeur

Université de Poitiers

\section{Référence électronique}

Geneviève Piché, «Religieuses et infirmières : des femmes dans un monde d'hommes », Images du

travail, travail des images [En ligne], 6-7 | 2019, mis en ligne le 01 février 2019, consulté le 14 avril 2021 URL : http://journals.openedition.org/itti/775 ; DOI : https://doi.org/10.4000/itti.775

Ce document a été généré automatiquement le 14 avril 2021

Images du travail, travail des images 


\section{Religieuses et infirmières : des femmes dans un monde d'hommes}

\section{Geneviève Piché}

\section{Anesthésie dans une salle de chirurgie, ca 1939}

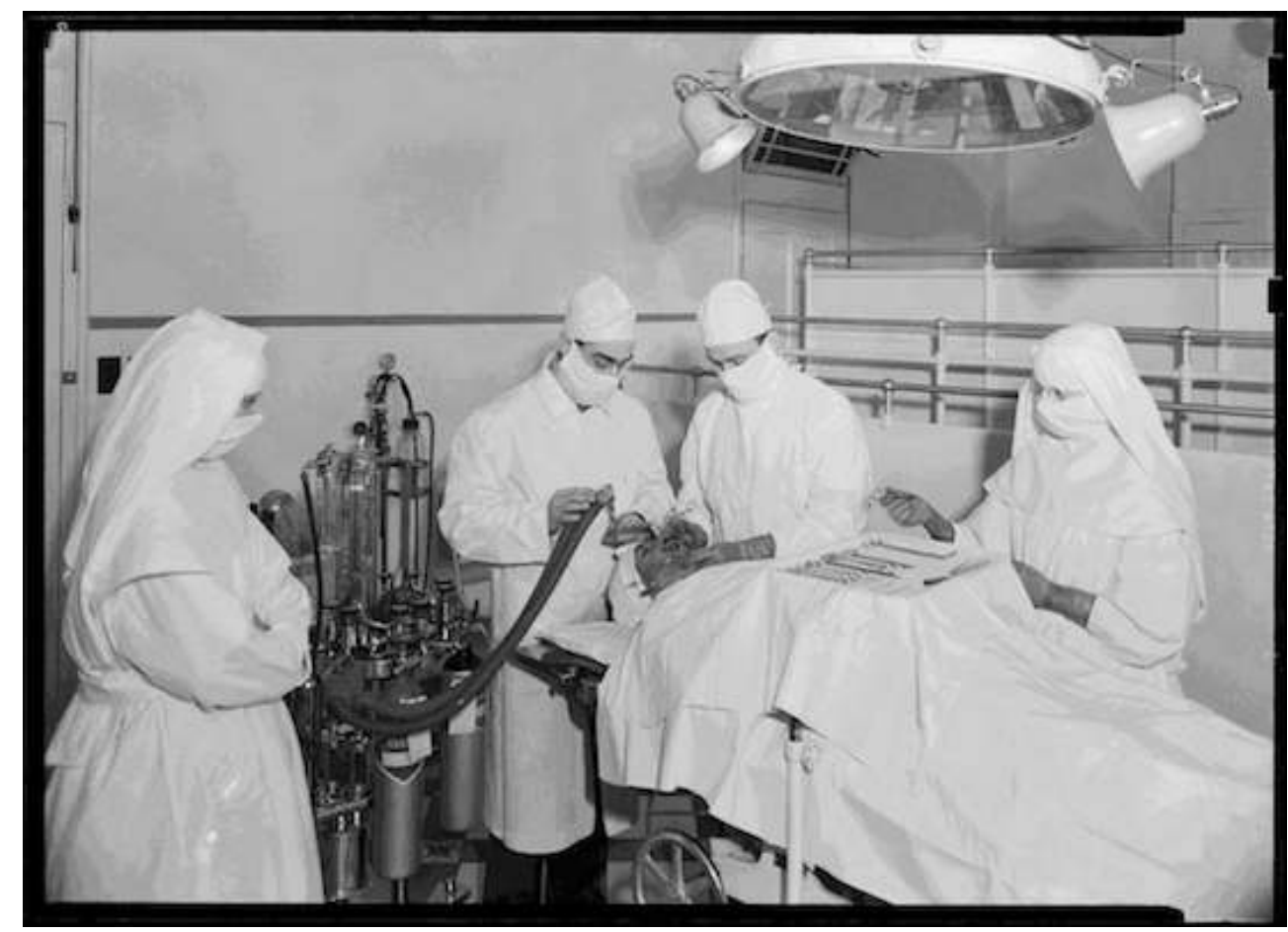

(c) Archives du Monastère des Augustines

En 1939, un appareil-photo s'immisce dans une salle de chirurgie de l'Hôtel-Dieu de Québec pour croquer sur le vif le chef anesthésiste en pleine opération, assisté par l'infirmière sœur Sainte-Denise. Les fonds d'archives du Monastère des Augustines conservent un éventail très large de ce genre de photographies, qui témoignent du travail des premières infirmières canadiennes. En filigrane de cette simple 
photographie, c'est une grande partie de l'histoire des soins infirmiers qui y est décrite. $A u$ début du XXe siècle, les exigences en médecine dans les hôpitaux se font de plus en plus rigoureuses et les médecins souhaitent dorénavant que les religieuses hospitalières effectuent plus de traitements ; ils réclament alors qu'elles suivent une véritable formation, qu'ils se proposent même d'offrir. C'est le début de l'École des Infirmières de l'Hôtel-Dieu de Québec. De 1904 à 1950, seules des religieuses pourront y obtenir un diplôme.

2 Que révèle ce cliché au sujet des conditions de travail des Hospitalières dans les années 1930-1940 ? Pourquoi celui-ci est un témoin plus bavard que les autres ? D'une part, l'image témoigne d'un monde scientifique majoritairement masculin, où l'infirmière évolue souvent en retrait, en appui, en silence. Administratrices de leurs hôpitaux, les Augustines demeurent toutefois les principales gestionnaires et la Mère Supérieure supervise le corps médical qu'elle emploie. D'autre part, l'image atteste l'importance de l'immense legs des communautés religieuses envers la société québécoise. Féministes d'avant-garde, les Augustines du Québec ont contribué à jeter les bases du système de santé québécois actuel, en fondant les plus grands hôpitaux de la province. Certes, le fait d'appartenir à une communauté religieuse cloîtrée les a soumises à certaines contraintes: le port peu pratique d'un costume religieux avec voile et tablier ou la difficulté de sortir du cloître pour se former et comparer leurs pratiques. Nonobstant ces limites, les Augustines ont ouvert la voie aux femmes, en contribuant significativement à l'émergence d'une profession typiquement féminine, qui le restera d'ailleurs jusqu'à la fin des années 1960 .

\section{AUTEUR}

\section{GENEVIÈVE PICHÉ}

Geneviève Piché est Responsable des archives au Centre de recherche en civilisation canadiennefrançaise de l'Université d'Ottawa et chargée de cours au département d'histoire de l'Université de Sherbrooke. Titulaire d'un doctorat en histoire de l'Université de Sherbrooke et d'un doctorat en études américaines de l'Université Toulouse-Jean Jaurès, elle se spécialise sur le monde catholique américain, du $18^{\mathrm{e}}$ au $20^{\mathrm{e}}$ siècle, et sur les écrits du for privé, notamment sur la correspondance d'hommes et de femmes d'Église. Ses recherches doctorales lui ont d'ailleurs valu le Prix de thèse de l'Institut des Amériques de Paris en 2016 et la publication de sa thèse aux Presses Universitaires de Rennes en 2018 sous le titre Du baptême à la tombe. Afro-catholicisme et réseaux familiaux dans les communautés esclaves louisianais. 